\title{
2666 de Roberto Bolaño: diálogos entre el caos y la forma a través de la "ficción encubrimiento"1
}

\section{Roberto Bolaño's 2666: Dialogues Between Chaos and Form Through the "Fiction Concealment"}

\author{
Álvaro Rodriguez \\ Pontificia Universidad Javeriana \\ aroestudiantes@gmail.com
}

\section{Resumen}

El presente artículo desarrolla un comentario crítico a las dos categorías fundamentales propuestas por Bolaño para el desarrollo de la novela 2666: lo intelectual y la otra racionalidad. Se propone un estudio sobre los modos en que el autor desarrolla el ámbito de la sociedad en las cinco partes que la componen, y utiliza las categorías movimiento aparente, lectura como puente, búsqueda, academia y Occidente, para crear una faceta de su universo narrativo. Igualmente, durante el análisis, el concepto de "encubrimiento" se expondrá como parte clave de la estética del autor y sustento de la propuesta interpretativa.

Palabras clave: metalepsis, ocultamiento, movimiento aparente, ética del arte, cultura y barbarie.

\section{Abstract}

This paper develops a critical commentary to the two fundamental categories proposed by Bolaño for the development of his novel 2666: intellect and other rationality. It proposes a study of the ways in which the author develops the society's domain in their five parts; explains how the categories apparent motion, reading as a bridge, search, academia and West, build a facet of his fictional universe. Moreover, during the analysis, the concept "concealment" will be discussed as a key part of Bolaños aesthetics and support of the interpretation.

Keywords: Metalepsis, Concealment, Apparent Motion, Ethics of Art, Culture and Barbarism.

1 El presente artículo está basado en el segundo capítulo de la tesis Exploración y análisis de la dicotomía intelecto-otra racionalidad en 2666 de Roberto Bolaño. La parte de Fate como zona narrativa de transito y la cuestión de lo visual en la novela. Pontificia Universidad Javeriana, Facultad de Ciencias Humanas, Maestría en Literatura, 2013. 


\section{Categorías de la razón. El ámbito de la sociedad}

El ejercicio de escritura crítica que se presenta a continuación se inscribe en la línea de análisis e interpretación literaria que propone Susan Sontag desde la siguiente cuestión:

¿Qué tipo de crítica, de comentario sobre las artes, es hoy deseable? Pues no pretendo decir que las obras de arte sean inefables, que no puedan ser descritas o parafraseadas. Pueden serlo. La cuestión es cómo. ¿Cómo debería ser una crítica que sirviera a la obra de arte, sin usurpar su espacio? (24-5).

Desde ese lugar de enunciación -lanzado al ámbito de la crítica en 1964, eso hay que recordarlo- el presente trabajo espera convertirse en material de inquietud para aquellos lectores que se hayan acercado antes a la novela, y de motivación para aquellos que aún no la han recorrido.

Así, es posible ver en 2666 una estructura compuesta por tres piezas: dos bloques y una zona de tránsito entre el primero y el segundo. Las cinco partes que conforman la obra, "Críticos", "Amalfitano", "Fate", "Crímenes" y "Archimboldi" se conectan a través de diversos temas y recursos narrativos que conducen a la exaltación y exploración de la dicotomía intelecto-otra racionalidad. Siguiendo esta lectura, la novela estaría constituida por un primer bloque en donde predomina temáticamente lo intelectual y un segundo bloque en donde lo que predomina es el universo de una realidad diferente a la convencional o racional. Ahora, estos dos ámbitos están conectados por una zona de tránsito, por un espacio narrativo en donde el mundo relatado va perdiendo las anclas intelectuales para sumergirse en el caos. Esta zona es la tercera parte de la novela, La parte de Fate.

La racionalidad y la locura, la realidad social y el extrarradio, la realidad real y la realidad otra no están separadas en la novela, todo lo contrario, están integradas, y para comprobarlo, el ejercicio de análisis enfilará rumbo hacia las construcciones conceptuales más importantes de la novela. De esta manera, indagar por el paso de lo intelectual a la otra racionalidad se convierte en la excusa fundamental de este artículo, motivo que también se puede enunciar de la siguiente manera: el universo ficcional de 2666 está sostenido por una realidad social permeada por la realidad del extrarradio. Una sospecha que promueve el narrador de La parte de los críticos: "A partir de ese momento la realidad... pareció rajarse como una escenografía de papel, y al caer dejó ver la que había detrás: un paisaje humeante, como si alguien, tal vez un ángel, estuviera haciendo cientos de barbacoas para una multitud de seres invisibles" (Bolaño 179).

El método de lectura y de organización “taxonómica” seguirá, de manera sutildiríamos escrupulosa- las mismas licencias analíticas utilizadas por Omar Calabrese en su libro La era neobarroca: 
¿cómo se puede comprender cuáles son los caracteres comunes de fenómenos diferentes? Se puede ir al azar, catalogando lo que alcancemos a intuir arriesgándonos a cada paso, o bien... se partirá desde un principio general que es el siguiente: si estamos en condiciones de advertir 'semejanzas' y 'diferencias' entre fenómenos que tienen, por otra parte, una apariencia lejanísima, entonces esto quiere decir que 'hay algo por debajo, que más allá de la superficie, existe una forma subyacente que permite las comparaciones y las afinidades. Una forma. Es decir, un principio de organización abstraído de los fenómenos que preside su sistema interno de relaciones (13).

Denominadas como categorías de la razón, se propondrá un estudio sobre los modos en que el autor desarrolla el ámbito de la sociedad en toda la novela y utiliza las isotopías movimiento aparente, lectura como puente, búsqueda, traductor-crítico y academia, y Occidente, para crear una faceta de su universo narrativo no exenta del influjo de la realidad otra, delirante y abismal. Gracias a los diálogos entre la razón y la locura, y a la mirada que de las formas del mal Bolaño desarrolla, es posible anudar la siguiente idea del húngaro Imre Kertész, a su apuesta ética y estética: "Hay quienes piensan de pronto seriamente que nuestra locura no es una sugestión dictada por fuerzas externas, sino que emerge desde nuestra propia alma; que es, pues, una necesidad de nuestra alma: y ahí empieza el mal irremediable" (132).

\section{Movimiento aparente}

Bolaño riega semillas de distracción en el relato. Logra que los lectores no pierdan de vista uno o varios indicios o acontecimientos que nunca se van a resolver. Así, toda la novela es una simulación, una apariencia. El relato es una apariencia de relato; es un relato que avanza en un relato que no se va a completar. Es en un segundo plano de la narración en donde todas las acciones, los sucesos, los acontecimientos tienen lugar: encontrar a un autor, comprender una escena de violencia, misterio y tal vez muerte, encontrar la razón de un libro (y su dueño), resolver actos criminales, comprender cómo se hace un escritor y cuáles son los requisitos para la inmortalidad. Llegar al sentido, ver, poseer los argumentos que llevan a la razón, a la luz.

Resolver, completar y redondear el relato nos regresa la sensación de tranquilidad y confianza que conlleva el sentido, el orden y la lógica. Bolaño insiste en que tal estado es improbable. Es un autor del realismo caótico, de la presencia inquietante e incuestionable de la pesadilla, del vacío. No hay verdades, ni absolutas ni parciales. Todo es un enorme disco mágico, un movimiento aparente hacia el sentido que nunca se alcanza, que se trunca, se corta, se deja en espera por falta de quietud en el tiempo y en el espacio.

El disco mágico es un símbolo que cubre o contiene toda la novela: una cara es la realidad racional, la otra cara es la realidad contundente y brutal del abismo, la realidad otra, y el punto de unión, lo que las hace girar y parecer una sola es la bisa- 
gra, el cordel. Esta es una de esas semillas lanzadas por Bolaño. Como presencia del ingenio en el movimiento aparente, el chileno propone la imagen conceptual y gráfica de un borrachito en prisión que sonríe: durante un diálogo entre dos personajes en La parte de Fate, Charly Cruz y el profesor Amalfitano, se afirma que

el borrachito se ríe porque nosotros creemos que está en prisión, sin apercibirnos
de que la prisión está en una cara y el borrachito en la otra, y que la realidad es ésa,
por más que hagamos girar el disco y nos parezca que el borrachito está encarcelado.
De hecho, podríamos incluso adivinar de qué se ríe el borrachito: se ríe de nuestra
credulidad, es decir se ríe de nuestros ojos (Bolaño 423).

El disco mágico como concentración del sentido del mundo, a la manera de los dibujos adivinanzas en Los detectives salvajes (1998).

El autor mueve el mecanismo que logra la apariencia de movimiento metafísico en la realidad ficcional; en Santa Teresa no hay lugar para la epifanía, por medio del narrador insiste en comentar y presentar la apariencia de continuidad, nos hace creer que dos sucesos están conectados por alguna razón o mecanismo desconocido, ignorado o misterioso para el relato. Entre dos anécdotas: el encuentro de Charly y Amalfitano, y la relación entre Rosa Amalfitano y Chucho Flores, el narrador se inclina por la segunda, dejando la propuesta estética oculta. Unir esos sucesos sólo es posible en la imaginación del lector crítico gracias a la estructura de la obra.

Este movimiento continuo de las dos caras de la realidad arroja de forma inevitable pero escasa luces sobre la presencia del caos dentro de la razón. Así lo comenta Carlos Franz sobre una escena de La parte de los críticos:

La ética bestial del fascismo y el esteticismo angelical de las vanguardias se tocan. Lo sabemos demasiado y B. no lo ignoraba. Hay que recordar, en 2666, el placer sexual de esos críticos que se sacuden del todo su pretencioso humanismo, pateando hasta casi matarlo a un taxista paquistaní en Londres. Recordar el placer furibundo de esos estetas, de esos dandis (105).

Esto tiene mucho que ver con la creación de la persona, con la unión entre la luz y la oscuridad, entre el orden y el caos pues Bolaño parece mostrar que a pesar de andar la ruta de la racionalidad, de la norma, la pulsión abismal siempre está cerca de la superficie de los comportamientos de sus personajes. Con un poco de espacio y sobre todo libertad de acción, hombres e instituciones llegan a su obra final: el mal propio, el mal personal. La conclusión entonces sería que el mundo racional occidental es la suma de contenciones, de controles, casi de represiones; en eso consiste su movimiento aparente y por eso es la primera categoría propuesta para la realidad social. Bolaño advierte que el abismo siempre está allí, al otro lado. La misión o la función del artista consiste entonces en crear puentes para poder observarlo, comprenderlo, y comprendernos; para explicar, como lo hace el sensato y loco Amalfitano que el borrachito se ríe de nuestra inocente y confiada mirada al mundo. 
En la novela, el espacio narrativo en donde el movimiento aparente se dispara es La parte de Fate. Todo en el relato del periodista norteamericano se impregna de ambigüedad y la realidad va perdiendo consistencia; así lo revela uno de sus entrevistados, el excombatiente de los Panteras Negras, Barry Seaman:

\footnotetext{
Podía tratarse de una estrella viva o podía tratarse de una estrella muerta. En ocasiones, según se lo mirara, dijo, ese asunto carecía de importancia, pues las estrellas que uno ve de noche viven en el reino de la apariencia. Son apariencia, de la misma manera que son apariencia los sueños (321).
}

¿Qué en la historia ya ha muerto y no lo hemos notado? ¿Qué en la historia sigue brillando a pesar de que ya no exista? ¿Cuál es la apariencia? ¿El caos o el orden? Seaman responde a estos interrogantes, que la noche de Santa Teresa devora, con poesía: "Las metáforas son nuestra manera de perdernos en las apariencias o quedarnos inmóviles en el mar de las apariencias" (Bolaño, 2666 322-3).

De todas partes surgen las señales de que nuestra mirada es peligrosamente confiada. Esta apariencia de engaño logra que en La parte de Fate una forma de violencia logre aliviar y encubrir otra: a la sociedad pertenece la pelea de boxeo, un evento que convoca a la prensa internacional hace parte de las válvulas de escape que ha creado la sociedad para que el edificio racional no colapse; los periodistas están felices y hacen apuestas. ¿Cuántos buscan información sobre los asesinatos? Todos saben que existen pero pocos hacen algo para aclarar y resolver la violencia. Por el contrario pretenden mantener la realidad en un estado inmóvil y silencioso:

\footnotetext{
los asesinatos de mujeres -dijo Chucho Flores con desánimo-. Florecen -dijo. Cada cierto tiempo florecen y vuelven a ser noticia y los periodistas hablan de ellos. La gente también vuelve a hablar de ellos y la historia crece como una bola de nieve hasta que sale el sol y la pinche bola se derrite y todos se olvidan y vuelven al trabajo (Bolaño, 2666 362).
}

¿Qué es el sol en esta alegoría? ¿La cotidianidad? ¿El peso de la sociedad que acalla las voces y profundiza los miedos? Nuestra incapacidad de vivir en el horror mirando con los ojos bien abiertos el precipicio.

En la forma de la novela resaltan los personajes que no permanecen, que pasan sin persistir por la realidad del relato; novela río, movimiento aparente como el disco mágico. Uno de los más trascendentes es el judío ruso Ansky, cuyos cuadernos encuentra el futuro Archimboldi. Para él el velo de papel se ha rasgado y puede contemplar la realidad otra. La relación entre la realidad y el deseo y la posibilidad de transformar la realidad imponiéndolo: "No se trata de creer... se trata de comprender y después cambiar" (Bolaño, 2666 895), opina. Este escritor invisible que prefigura a Archimboldi le transmite la idea de que comprender es permanecer con los ojos abiertos en medio del abismo, de estar atento al caos y al horror para buscar su sentido y modificarlo: "La posibilidad, no obstante, de que todo aquello no fuera otra 
cosa que apariencia lo preocupaba. La apariencia es una fuerza de ocupación de la realidad... El nacionalsocialismo era el reino absoluto de la apariencia" (Bolaño, 2666 926). Si La parte de los críticos está enmarcada en el pensamiento académico, La parte de Archimboldi es su versión en negativo, la que sólo se puede ver en un sueño o una pesadilla rodeada por la muerte, el reflejo de la maldad estética: mientras los críticos de la primera parte quieren hacer brillar al autor, en la quinta el sistema quiere hacer brillar su ideología usando al autor. En este orden de ideas la cuarta parte sería el reflejo negativo, la versión opuesta, oscura y caótica del universo racional del profesor Amalfitano. La conclusión de Reiter-Archimboldi será el reflejo de la que escribió el judío ruso en su cuaderno refiriéndose a la pintura de Archimboldo como el fin de las apariencias: "Sólo el vagabundeo de Ansky no es apariencia... Ansky vivió toda su vida en una inmadurez rabiosa porque la revolución, la verdadera y única, también es inmadura" (Bolaño, 2666 926).

Bolaño, un joven rabioso que vivió para y por la revolución, exploró en sus obras el mecanismo dañino y doloroso de la Historia que convierte la realidad en una zona de duda permanente; ¿de qué otro modo se puede entender que haya utilizado más de ciento cuarenta veces la construcción "en realidad" a lo largo 2666? Integrar, o "empotrar" el enunciado "en realidad" es una manera prudente de señalar que lo que parece ser no es. La lucha ética y estética del chileno consiste en parte en dejar al descubierto la realidad otra, la del espanto, sin que el lector se eche a correr. Para esto aplica el encubrimiento. Juego y esfuerzo delirante que pretende encubrir una realidad para dejarla al descubierto y hablar del procedimiento mientras se ficcionaliza: "En las entrañas del hombre que escribe no hay nada... su novela o poemario... salen no por un ejercicio de estilo o voluntad, como el pobre desgraciado cree, sino gracias a un ejercicio de ocultamiento" (Bolaño, 2666 983), sentencia uno de sus personajes.

\section{Lectura como puente}

Para Bolaño la obra de arte es el puente y la lectura una metáfora de la acción de permanecer con los ojos abiertos en medio del abismo. El libro está en las cinco partes de la novela así como su consecuencia y acción natural: la lectura. Se erige compañero, personaje principal o secundario, telón de fondo, ambiente, color, tono focal. Ayuda a formar el paisaje intelectual. En los críticos es, además de elemento generador de acciones para la narración, objeto de culto, fin del camino, aceptación de la condición azarosa de la realidad y regreso o llegada a las tranquilas playas de la forma, del sometimiento de la casualidad por medio de la escritura. Tal es el final de Pelletier en el hotel de Santa Teresa, en eso consiste la conclusión que comparte con Espinoza: "Archimboldi está aquí -dijo Pelletier-, y nosotros estamos aquí, y esto es lo más cerca que jamás estaremos de él” (Bolaño, 2666 207). 
En Amalfitano es el objeto que anula el caos y aleja el mal, y a la vez la evidencia más contundente de la historia del horror, el producto engendroso que la sociedad crea para anular a la humanidad que está por fuera de la sociedad. En Fate el libro es la compañía del protagonista en su viaje hacia el abismo, y una pulsión que le recuerda su pertenencia al extrarradio: su historia es la historia de los que perdieron la vida. En los crímenes es el hallazgo que hace el personaje Lalo Cura y que lo diferenciará de la jauría y la recua de sus compañeros de oficio. La lectura que hace el muchacho salvaje de los libros sobre investigación forense se constituye en la guía para mirar las señales del abismo de manera más acertada, pero también la herramienta para notar y luego confirmar que la autoridad y la ley no están del lado de los detectives; que también ellos hacen parte de los "fuera de la sociedad". Finalmente, en Archimboldi el libro aparece en su faceta más primitiva: el cuaderno, el borrador, el no libro que se lee. Lectura resguardo, "capa protectora" que permite a Reiter descubrir que ante la muerte y el horror el suicido no es la única vía, y que escribir es una manera de hacer cara al caos.

En 2666 Bolaño insiste en la posibilidad del libro como instrumento liberador, como arma para luchar contra el horror y la historia. Sin embargo, no descuida una de sus isotopías favoritas: el libro como síntoma de la Historia y del mal institucional. Esto lo comenta Juan Villoro en la siguiente afirmación:

\footnotetext{
en la Latinoamérica de las dictaduras Bolaño despliega una galería de infames capaces de conjugar con elegancia la gramática de la tortura. Enemigo de las simplificaciones, crea sujetos facetados, poliédricos: Wieder, el poeta que escribe versos con la cauda de su avión en Estrella distante es tan opresor como artista. En él la creatividad coexiste con la depredación (85).
}

Esta categoría de los autores y las obras aberrantes aumenta con el libro de Lonko Kilapán, autor chileno leído por el profesor Amalfitano en la segunda parte de la novela, y que resulta de la violación a la memoria y a la tradición que Pinochet, y sus piezas en el poder, comete en la cultura chilena. A esta conclusión llega el lector Amalfitano quien atina a proponer "que Kilapán tal vez no hubiera escrito ese libro... también era posible que Kilapán no existiera... Todo falso. Todo inexistente... La prosa de Kilapán, sin duda, podía ser la de Pinochet... o la de cualquier neofascista de la derecha" (286-7).

Junto a la escritura sometida del fantasma Kilapán, como reflejo y espejo la prosa sometida de Ivanov, el plagiador de la quinta parte, quien ansía la fama a costa de la integridad de la obra literaria. Ahora, a estas dos formas del mal estético se contrapone la figura del intelectual del abismo, del lector salvaje, el periodista y el detective que quieren comprender, o el soldado durante la guerra, prófugo de la misma, el escritor invisible que logra permanecer con los ojos abiertos mirando el precipicio.

Novela de reflejos metaficcionales, del movimiento aparente, Bolaño nos muestra cómo ha sido leer 2666: 
Probablemente, pensó Lalo Cura mientras leía el libro alumbrado por una exigua bombilla,... el mismo Söderman ya estuviera muerto hacía tiempo y él nunca lo sabría. Pero eso no importaba, al contrario, esa falta de certeza se convertía en un acicate más para leer. Y leía y a veces se reía de lo que decían el sueco y el gringo y otras veces se quedaba maravillado, como si le hubieran dado un balazo en la cabeza (548).

Una vez más la imagen de los ojos abiertos, la maravilla en la revelación de un misterio efímero, y la función desgraciada del autor como puente: en la escritura no hay placer, parece decirnos el viejo ex escritor de La parte de Archimboldi que renuncia a crear obras menores para no sentirse mero copista:

Sí, un plagio, en el sentido de que toda obra menor, toda obra salida de la pluma de un escritor menor, no puede ser sino un plagio de cualquier obra maestra. La pequeña diferencia es que aquí hablamos de un plagio consentido. Un plagio que es un camuflaje que es una pieza en un escenario abigarrado que es una charada que probablemente nos conduzca al vacío (985).

Cuando el viejo habla de las obras menores y de los escritores de dichas obras las propone como necesidad de ocultamiento, como elemento clave de la apariencia del bosque que es la literatura, y deja al autor como simple herramienta de dicho encubrimiento.

En La parte de los crímenes hay un personaje maravilloso, mezcla de una fuerza indestructible y una inocencia impoluta; en otras palabras, una bomba de tiempo ficcional. Se trata de Florita Almada, quien "Veía cosas que nadie más veía. Oía cosas que nadie más oía. Y sabía buscar una interpretación coherente para todo lo que sucedía" (535). Esta psíquica homeopática reconoce en sus sueños mensajes acerca de la verdad sobre los crímenes de Santa Teresa y, agobiada por esa información, decide hablar. Sin embargo, lo que dice es la apariencia de una verdad. Al pasar por dos filtros, el de la memoria del sueño y el de la verbalización de lo soñado, sus "imágenes" son vacuas. En Florita Almada Bolaño signa un reflejo o una sombra del lector: somos los ordenadores del mundo ficcional narrado, creemos que el libro merece una mirada analítica para poner las cosas en su lugar y poder comprenderlo. A pesar de que el autor da una forma particular al caos, al destino, al azar y al dolor, y nos presenta su novela, nosotros creemos que no es suficiente y damos un nuevo orden particular, creemos que es válida una nueva estructura, ahora no ficcional, un puente para poder ver el puente y el abismo al tiempo. Eso es la interpretación. Somos para Bolaño, en su imaginación, en el fondo de sus deseos y sus pensamientos Floritas Almadas, viejecitas, encantadoras, amabilísimas e inofensivas que hablamos sobre lo que vemos creyendo que con eso solucionamos el misterio de la obra de arte. Y como ella somos incompetentes "pues vidente significaba alguien que veía y ella a veces no veía nada, las imágenes eran borrosas, el sonido defectuoso” (Bolaño, 2666 535). Susan Sontag parece estar de acuerdo con la burla que hace Bolaño a los deseos 
de toda lectura: "debe advertirse que la interpretación no es sólo el homenaje que la mediocridad rinde al genio. Es precisamente, la manera moderna de comprender algo, y se aplica a obras de toda calidad" (20).

Lecturas que agreden al libro, que quieren sentenciar la interpretación a una sola y rotunda imagen, que hacen del contenido del libro el objeto que debe ser descubierto, el lugar en el que se encuentra el sentido o la respuesta al misterio, pues "aún se supone que una obra de arte es su contenido. O, como suele afirmarse hoy, que una obra de arte, por definición, dice algo" (Sontag 15). ¿Cuál sería entonces la lectura que en lugar de enterrar para siempre la obra la hace brillar en sus múltiples caras? Quizá la que hace Pelletier al final de la primera parte de la novela: su ejercicio no es académico ni crítico, se acerca en cambio a la contemplación activa. Es pura y poderosa lectura hedonista: anulación del dolor y del horror. Lectura que da la espalda a la forma de interpretación institucional:

\footnotetext{
En la mayoría de los ejemplos modernos, la interpretación supone una hipócrita negativa a dejar sola la obra de arte. El verdadero arte tiene el poder de ponernos nerviosos. Al reducir la obra de arte a su contenido para luego interpretar aquello, domesticamos la obra de arte. La interpretación hace manejable y maleable al arte (Sontag 19).
}

La lectura hedonista, la lectura como puente no pretende domesticar la obra de arte, todo lo contrario, pretende explorarla para iluminar sus rincones y abrir sus ventanas; en la novela los personajes que descubren o encuentran esta forma de comprensión del texto escrito también hallan una comprensión más amplia de la realidad caótica y dolorosa.

\section{Búsqueda}

Como una constante en la obra de Bolaño, sus personajes, concretos o fantasmales, realizan la búsqueda del otro, de lo otro, que permitirá el hallazgo inesperado de la verdad personal, de la revelación que se puede no entender. Así en 2666, eso otro inicial, Archimboldi para el caso, pasa a ser aquello que no se alcanza, que no se encuentra, una suerte de excusa narrativa y existencial, y un tono estético. La búsqueda en Santa Teresa se transforma en pausa, en reflexión y goce. Los personajes tienden al estatismo estoico. Una suerte de calma y humildad en donde lo inmediato es lo único por lo cual vivir. Es esta una constante en la obra de Bolaño: la ilusión de una búsqueda, la promesa eterna que hace la novela a su lector, y el proceso lento hacia el reconocimiento de que la búsqueda no es trascendental. No hay fracaso. Por eso en Los detectives salvajes encontrar a Cesárea Tinajero no conduce a nada más que a seguir avanzando, por eso la aceptación de los críticos ante la imposibilidad de conocer a Archimboldi; los únicos frustrados somos los lectores. Los personajes de Bolaño no se frustran, por el contrario, llegan a un estadio más alto: el goce de la ironía y del pesimismo que no afecta la salud. 
Por su parte ¿qué se busca en Amalfitano y Fate? El sentido, eliminar o aplacar el caos. ¿En qué consiste la búsqueda de Amalfitano? ¿La reconoce o sólo la intuye? ¿Se trata de la búsqueda de la historia chilena? ¿Su ser no ser chileno, puesto que es todo europeo y vive en el exilio? Lanzados a un destino que no quisieron controlar, también quieren comprender, cada uno con sus armas personales. El precio del hallazgo será el vacío. El mismo que padecerán los buscadores de La parte de los crímenes: detectives, periodistas, mujeres desesperadas por comprender. En la realidad otra, en el abismo de Santa Teresa buscar la respuesta o el sentido se convierte en la lucha contra la apariencia. Los personajes se pueden agrupar en los muertos vivientes que aceptan los hechos y en los buscadores que guardan la sospecha de que algo está siendo manipulado y tergiversado, y que la vida bien vale la pena gastar en dicho viaje.

Por último, la búsqueda en la quinta parte es exclusiva del lector. El valor enorme de La parte de Archimboldi radica en que el paso último hacia adelante, el último avance, la última jugada en su ajedrez personal contra la muerte Bolaño la dedica al lector. El último y más importante buscador, el último y más grande detective. El último que, en definitiva, determina qué obras viven y perviven y qué obras mueren o se extinguen en poco tiempo. Luego de las cuatro partes anteriores, especialmente de la primera y la segunda, el lector quiere encontrar a Archimboldi, quiere ganarles a los críticos y dar con el autor. No lo logra. Fracasa. Como Ulises Lima y Arturo Belano buscadores y halladores de Cesárea Tinajero, encuentra, pero no encuentra. Toda la quinta parte es un esfuerzo enorme del lector por dar con el creador y el hallazgo no le marca ningún hito en su experiencia. Debe seguir, debe perderse en el mundo como Lima y Belano; debe hacer el mundo recorriéndolo, lo que significa para él, leer. Hasta la muerte. El lector recorre en la quinta parte trescientas y algo más de páginas buscando el secreto, esperando el sentido del escritor, leyendo entre líneas, adentrándose, sumergiéndose en el texto, en lo que está dicho, por lo que está dicho, y al final no logra aquello. Debe continuar. La obra se ha agotado. Debe leer de otra manera. Archimboldi, la persona de Archimboldi, no tiene nada que decirnos, la obra todo.

2666 es el ordenamiento, no el caos, pero permite señalar el caos que es el mundo real, hace notar cómo la gran máquina racional deja algunas grietas que permiten ver el horror, el otro lado, que también es parte de lo humano. El valor del enigma que es eternamente así. Esta certeza no anula la necesidad, el deseo y el placer por buscar.

\section{Traductor-crítico y Academia}

En el primer mega-bloque de la novela (partes uno y dos) Bolaño crea un mundo que le fue ajeno, un mundo al cual nunca perteneció: el de la academia. El de jóvenes doctorados que alcanzan el éxito o el reconocimiento en su área. Lo único que comparte con ellos es la voluntad de hierro: 
Se vio [Pelletier], como queda dicho, a sí mismo, ascético e inclinado sobre sus diccionarios alemanes, iluminado por una débil bombilla, flaco y recalcitrante, como si todo él fuera voluntad hecha carne, huesos y músculos, nada de grasa, fanático y decidido a llegar a buen puerto (17).

Es en esta voluntad donde todos se igualan, académicos, autores, pintores, críticos, en donde todos los grandes y positivos personajes de Bolaño se reconocen como hermanos. Sus héroes -si es posible usar este concepto para la literatura del siglo XXI- como tanto le gustaba a él mencionar, entran al cuarto oscuro y aterrador de la realidad con los ojos y los oídos bien abiertos. Poetas olvidados, críticos reconocidos, escritores invisibles, todos han pasado por la prueba de fuego de la vida cruel y salvaje de los desposeídos, y cruzan al otro lado de la realidad y de la comprensión. A Bolaño este tránsito lo condujo a la gran literatura y posiblemente a la enfermedad y la muerte.

Iniciados en el conocimiento del gran arte, estos críticos salvajes también ponen a prueba la literatura:

¿Cómo reconocer una obra de arte? ¿Cómo separarla, aunque sólo sea un momento,
de su aparato crítico, de sus exégetas, de sus incansables plagiarios, de sus ningunea-
dores, de su final destino de soledad? Es fácil. Hay que traducirla. Que el traductor
no sea una lumbrera. Hay que arrancarle páginas al azar. Hay que dejarla tirada en
un desván. Si después de todo esto aparece un joven y la lee, y tras leerla la hace
suya, y le es fiel (o infiel, qué más da) y la reinterpreta y la acompaña en su viaje a los
límites y ambos se enriquecen y el joven añade un gramo de valor a su valor natural,
estamos ante algo, una máquina o libro, capaz de hablar a todos los seres humanos:
no un campo labrado sino una montaña, no la imagen del bosque oscuro sino el
bosque oscuro, no una bandada de pájaros sino el Ruiseñor (Bolaño, Entre 223-4).

En estas palabras late un eco o una prefiguración de la primera parte de 2666: el crítico debe ser también un traductor. Una idea prototípica o un adelanto secreto de su último trabajo, o una idea fija, fuerte y permanente, de esas que tienen el poder de, parafraseándolo, tomar al escritor del pelo y levantarlo a pesar de que todo esté perdido, cuando el cuerpo no quiere seguir.

El inicio de 2666, entonces, puede leerse como un homenaje al único y verdadero creador del canon; al lector que reescribe la obra para que pase por el fuego de la cultura y adquiera con la forja traductora su solidez y flexibilidad, así como su perdurabilidad. Los críticos en su novela son traductores y esto para Bolaño es clave. Son lectores superespecializados. Lectores absolutos que peligrosamente buscan entender la obra en su totalidad y revolucionar el canon:

Un clásico, en su acepción más generalizada, es aquel escritor o aquel texto que no sólo contiene múltiples lecturas, sino que se adentra por territorios hasta entonces desconocidos y que de alguna manera enriquece (es decir, alumbra) el árbol de la 
literatura y allana el camino para los que vendrán después. Clásico es aquel que sabe interpretar y sabe reordenar el canon (Bolaño, Entre 166).

Ahora, para completar la escenografía del mundo de la academia, el autor expone el abismo de la interpretación por medio de una ficción metacrítica. Él, habitante de la realidad otra junto con los poetas malditos, los escritores suicidas, las prostitutas y los detectives, no deja de poner en tela de juicio la labor de lo que denomina "literatura crítica ultraconcreta" (79): entre conferencias, encuentros, plenarias, congresos, revistas especializadas, se menciona un "curioso artículo" publicado por "un crítico serbio hasta entonces insignificante" (78). Un artículo que, como parte de otra metalepsis dentro de la metalepsis, es espejo y reflejo, plagio inconsciente, de un viejo artículo sobre la comprobación de la existencia de Sade en este planeta; los críticos ven una copia de dicho texto en el texto del crítico serbio quien hace la demostración de la existencia de Archimboldi. Un escrito curioso publicado en una revista especializada que exhibe las pruebas periodísticas de la existencia del autor en el primer plano de realidad ficcional. Al final de este micro-relato, la reflexión del narrador:

literatura no especulativa, sin ideas, sin afirmaciones ni negaciones, sin dudas, sin pretensiones de guía, ni a favor ni en contra, sólo un ojo que busca los elementos tangibles y no los juzga sino que los expone fríamente, arqueología del facsímil y por lo mismo arqueología de la fotocopiadora (79).

Sencilla y contundente declaración de guerra, Bolaño advierte a los académicos que ven en la reflexión crítica un obstáculo para su escritura de periodismo cultural, que esa labor y ellos junto a ésta, como la del serbio y el francés que "hizo real a Sade", serán "definitivamente borrados por el tiempo" (79).

Para el chileno la labor fundamental de la crítica es promover una obra valiosa. Tal vez parezca demasiado obvio pero es posible que la sociedad piense en el crítico no como un promotor y sí como un Minos cultural que ubica a cada desgraciado escritor en su correspondiente círculo infernal. Bolaño, en este gigantesco laboratorio de realidades, en este mundo personal de 1.100 y algo más páginas -como el protagonista de la película Synecdoche, New York quien intenta crear una obra que refleje en todos los detalles posibles la vida real- crea un lugar para las tendencias superficiales y cuasi faranduleras que miran en la literatura otro producto para satisfacer a una audiencia mórbida y alienada, y sentencia por medio de su narrador: "Hay que hacer investigación, crítica literaria, ensayo de interpretación, panfletos divulgativos si así la ocasión lo requiere, pero no este híbrido entre fantaciencia y novela negra inconclusa" (82).

¿Qué pasa con el crítico traductor en la realidad otra? Con Amalfitano, Bolaño quiere mostrar al traductor dañado. A la víctima de Latinoamérica. Siguiendo a George Steiner (1992) y su idea sobre la inhumanidad generada en parte por el estudio 
y la enseñanza de la literatura, incluso por el simple acto de la lectura, Bolaño lleva al abismo a la crítica literaria para demostrar su negativo, su sombra y su apariencia: el profesor Amalfitano expone a los críticos europeos la realidad de los intelectuales latinoamericanos que se entregan al poder institucional y colaboran en la construcción del mal. En su delirante parodia a la caverna de Platón (161 y ss.) Bolaño, a través de Amalfitano, retoma y concluye un tema fundamental de toda su obra y que tiene en el protagonista de Nocturno de Chile (2000) al arquetipo del "intelectual sin sombra"; así lo reconoce Edmundo Paz:

[en Nocturno de Chile] se encuentra una lúcida reflexión sobre las perversas relaciones que existen en América Latina entre el poder y la letra. Nuestros intelectuales han terminado más de una vez seducidos por el poder. Se han escrito grandes, fascinantes -y fascinadas- novelas sobre el dictador latinoamericano, pero muy poco sobre la figura a su sombra, el amanuense de turno, el intelectual cortesano, el que le escribe los discursos al gran hombre" (15).

\section{Occidente}

En una escena de La parte de los crímenes el periodista Sergio González "mientras leía a George Steiner, recibió una llamada que al principio no supo identificar" (674). Se trata de Klaus Hass que lo contacta desde la cárcel de Santa Teresa: "Una voz muy excitada y con acento extranjero decía todo es mentira, todo es una trampa, no como si acabara de llamarlo sino como si llevara media hora hablando" (674). González tarda un poco en identificarlo y luego le dice "yo ya no escribo sobre los crímenes de Santa Teresa" (674). Esta comunicación inevitablemente reactivará en el periodista la rueda de la obsesión por las mujeres muertas, rueda que se detendrá sólo con su muerte siete años más tarde. El periodista lee a un pensador del horror del siglo XX. La narración nos permite jugar e imaginar que González esa noche, tal vez, estuviese leyendo: "Para mí, el clamor más obsesivo, más profético del siglo XIX es la frase... ¡antes la barbarie que el tedio!” (Steiner, En el castillo 27).

George Steiner insiste en que veamos los hábitos y productos sociales de occidente con nuevos lentes: "La muerte novelística nos podrá conmover más poderosamente que la muerte en el cuarto de al lado. Así, puede existir un vínculo oculto, traicionero, entre el cultivo de la reacción estética y el potencial de inhumanidad personal" (Lenguaje y silencio 79). Europa como cultivadora de la ficción escrita a la que se opuso, por ejemplo, Bertolt Brecht y que luego de la lección de abismo del holocausto llevó a las declaraciones de silencio de Samuel Beckett. En otras coordenadas, Latinoamérica habitando la hibridez de una cultura mística, violenta, silvestre e histórica que produce los seres sin sombra relatados por Amalfitano en su diatriba a la cultura politizada, $y$ Norteamérica perpetuada en su pensamiento pop, sus argumentos superficiales, su televisión basura, su odio a la diferencia y su intrascendencia. 
El escenario del horror pasó de ser Europa en el siglo XX a ser Latinoamérica en el XXI. Bolaño nos muestra ese tránsito y señala constantes en el alma humana, formas de conducta que para Steiner surgen del aburrimiento: "Mi tesis sostiene que ciertos orígenes específicos de lo inhumano, de la crisis de nuestro tiempo que nos obligan a redefinir la cultura, se hallan en la larga paz del siglo XIX" (En el castillo 24-25). Una planicie sin avance cultural, un mar paralizado e interminable en donde el espíritu transformador se hace nostalgia: “¿Cómo puede un intelectual sentir dentro de sí algo de genio de Bonaparte, algo de esa fuerza demoniaca que lo condujo desde la oscuridad al imperio, y no ver ante él más que la chata rutina de la burocracia?" (En el castillo 34). Para el chileno la ciudad de la frontera es metáfora del caos y origen de la metáfora al mismo tiempo: escenario en donde el disco mágico con las dos caras de la realidad se pone en movimiento, la racionalidad occidental se construye con las formas del aburrimiento, su reverberación y la explosión de horror consecuente. Fate escucha un relato sobre un boxeador mexicano, un "tipo que medía casi dos metros. Algo nada usual en México, donde la gente es más bien bajita” (364). La anécdota la cuenta un periodista norteamericano como él. Desde el principio su relato toma visos racistas:

Poco a poco los presidentes de México serán cada vez más altos... A veces la cabeza de un presidente de México apenas estaba unos centímetros por encima del ombligo de un presidente de los nuestros... Ahora, sin embargo, la clase alta mexicana está cambiando. Son cada vez más ricos y suelen buscar esposas al norte de la frontera. A eso le llaman mejorar la raza (364).

Una anécdota laboral, un relato de medio tiempo que entra en el vórtice del horror:

La clase alta mexicana... está haciendo, por su cuenta y riesgo, lo que hicieron los españoles, pero al revés. Los españoles, lascivos y poco previsores, se mezclaron con las indias, las violaron, les metieron a la fuerza la religión, y creyeron que de esta manera el país se volvería blanco... Pero se equivocaron. Nunca puedes violar a tantas personas... Además ellos violaban de abajo hacia arriba, cuando lo más práctico, está demostrado, es violar de arriba hacia abajo (365).

Digna de un guión cinematográfico de D.W. Griffith ${ }^{2}$, la historia va llegando a su fin mientras deja a todo el mundo en el lugar que su relator considera le corresponde. Fate interviene:

¿Tú qué eres, un publicista del Ku Klux Klan?... Bueno, bueno, bueno, otro negrata susceptible, dijo el periodista. Fate trató de acercarse a él y darle, al menos un puñetazo... pero los periodistas que rodeaban al que había contado la historia se lo impidieron. Es sólo una broma, oyó que decía alguien. Todos somos americanos. Aquí no hay nadie del Klan. O eso creo. Luego oyó más risas (366).

2 Director norteamericano de principios del siglo XX cuyo film El nacimiento de una nación presenta marcadas tendencias racistas. 
¿Existe alguna justificación para esta forma del mal? El periodista Chuck Campbell trata de aliviar a Fate: "No tomes a mal lo que acabas de escuchar, muchacho... Ser corresponsal de deportes es aburrido y uno suelta disparates sin pensarlo dos veces... En ocasiones, sin querer, decimos barbaridades" (367). El aburrimiento que conduce al humor del abismo que conduce a la simetría de la destrucción que conduce a anulación de lo que consideramos humano; como los chistes contra las mujeres que se cuentan los policías de Santa Teresa.

La novela, siguiendo las ideas de Steiner, señala que al caer en el aburrimiento el espíritu humano se enfrenta con el horror del mal y la destrucción: "El cuerpo presentaba señales claras de tortura, con múltiples hematomas en brazos, tórax y piernas, así como heridas punzantes de arma blanca (un policía se entretuvo en contarlas y se aburrió al llegar a la herida número treintaicinco)" (724). Con una claridad dolorosa, Bolaño condensa en la figura de ese policía desocupado el espíritu tutelar del manicomio latinoamericano: la espera, el tedio, el humor del abismo que pretende sacudir del cuerpo el tedio, y el inevitable retorno a él.

Steiner ve en este ciclo el motor de la máquina que destruye a la cultura:

Las estructuras de la decadencia son tóxicas. Necesitando el infierno, hemos aprendido a construirlo y hacerlo funcionar en esta tierra... Ninguna otra capacidad del hombre representa mayor amenaza. Como la poseemos y la estamos usando en nosotros mismos, nos encontramos ahora en una poscultura. Al colocar el infierno sobre la superficie de la tierra, nos hemos salido del orden primordial y de las simetrías de la civilización occidental" (En el castillo 78-9).

El paso que da el chileno en toda la reflexión crítica sobre la decadencia de Occidente consiste en señalar que el centro del horror, el abismo (Bolaño se aleja de la mentalidad judeo-cristiana y no usa el término "infierno") ya no está en Europa sino en Latinoamérica. Y da continuidad a la idea de que una posible comprensión del horror contra la mujer se encuentra en las ideas de un "gran ennui" latinoamericano.

En 2666 la exploración ética y estética al tedio se concentra en las partes cuatro y cinco que terminan por ser espejo y reflejo del abismo. Siguiendo a Steiner, lo que se narra allí hace parte de las evidencias del origen de la poscultura. En La parte de Archimboldi Bolaño imagina y hace literatura a partir de dos cuadros que heredamos de la segunda guerra mundial: uno es el banquete del horror, puesta en escena que tiene seguramente en Saló o los 120 días de Sodoma su forma estética más compleja y completa. Con el placer del felino que captura y devora a su presa, el relato conduce a los oficiales del eje y a su cultísima compañía a un castillo rumano, corazón de los muertos vivientes. El segundo cuadro es el de la ejecución de los judíos. El chileno le da vida y voz a Leo Sammer, el administrador alemán quien perfecciona, en medio del derrumbe y el incendio de Europa, los placeres del tedio:

Los dejé hablar, tomé mi café tranquilamente, partí un pan por la mitad y lo unté con mantequilla y me lo comí. Después le puse mermelada a la otra mitad y me la 
comí. El café era bueno... Cuando terminé les dije que todas las posibilidades habían sido tenidas en cuenta y que la orden de deshacerse de los judíos griegos era tajante. El problema es cómo, les dije. ¿Se les ocurre a ustedes alguna manera? (949-50).

Sammer parece esperar el advenimiento de la idea que le permita solucionar el imprevisto laboral:

Dejé pasar dos días sin tomar ninguna determinación. No se me murió ningún judío... Poco más hice, que yo recuerde. Una enorme sensación de aburrimiento se fue apoderando de mí... Ya ni siquiera pensaba en mi hijo muerto en Kursk... Así pasaron dos días de inactividad que fueron como un sueño y que decidí prolongar otros dos días más (950-1).

Luego de esta etapa de letargo, auxiliado por el sueño del hijo muerto, Sammer llega a su versión personal de solución final: Bolaño crea el escabroso relato de los niños borrachos.

Hacer de su creación abismal, de su máquina de muertes personal, una experiencia verbalizada le cuesta la vida al nazi. El futuro Archimboldi asesina con sus propias manos al burócrata quizá por haber utilizado la palabra -herramienta de la cultura, su origen, su difusora y su protectora- para explicar y justificar su historia de horror. El prisionero Reiter ve en el acto verbal de Sammer una duplicación del crimen. Es inaceptable, debe morir, de su boca no deben volver a salir esas frases, tal vez porque relatar la destrucción del ser humano hace aceptable el horror:

Cuando salieron clandestinamente de Polonia los primeros informes sobre los campos de la muerte, la gente en general no creyó en ellos: semejantes cosas no podían ocurrir en la Europa civilizada de mitad del siglo XX. Hoy es difícil imaginar una bestialidad, una demencia de opresión o de repentina devastación en la que no creamos, que no coloquemos en el orden natural de los hechos. Moral y psicológicamente es un hecho terrible el de nuestra incapacidad de asombro. Inevitablemente el nuevo realismo conspira con lo que es, o debería ser, por lo menos aceptable en realidad (Steiner, En el castillo 94).

¿Qué es la historia en nuestra época? Algo como el libro de Lonko Kilapán: O’Higgins es araucano. 17 pruebas, tomadas de la Historia Secreta de la Araucanía. Por un lado, y tal vez para darnos más elementos de prueba, el texto aparece ante nuestros ojos como aparece a los ojos de Amalfitano, es decir, con todas sus marcas textuales. Nos enteramos también que para el profesor chileno este libro revisionista, leído por primera vez en 1978 fue objeto de burla, un divertido disparate producto de su país natal. 20 años más tarde, debido a sus nuevas condiciones metafísicas y existenciales, lo recuerda y lo repasa, no sin risa, con mayor atención. Dicha obra, la de Kilapán, pretende relacionar, hibridar la cultura occidental clásica y la cultura nativa precolombina de Chile. De forma peregrina su autor realiza conexiones etimológicas, geográficas e 
históricas entre las dos culturas para evidenciar la línea directa entre los mapuches y los griegos. Ejemplo perfecto de la violencia del poder sobre la memoria y la realidad. ¿Cómo enfrentarse a este engendro y a los otros creados por el totalitarismo? Lo único posible sería crear una forma desde la memoria personal y cultural.

¿El libro de Kilapán es una burla a la tendencia de los suramericanos de soñarse europeos?, o ¿es una evidencia, un triste y vergonzoso pasaje de anulación de lo indígena durante la dictadura? Con este producto de la historia Bolaño busca dar luces sobre el delirio fascista de Pinochet y sus funcionarios; en últimas de todo el país en decadencia. Fractal de todo Occidente, Lonko Kilapán puede ser cualquiera menos un mapuche, y la historia es lo que el fascismo diga que es. Así, parafraseando a Walter Benjamin, este documento de la cultura, es también un documento de la barbarie.

Parece no haber alternativa o escapatoria al espiral descendente de la salud mental de Occidente, pero Bolaño no hace loas al caos sino monumentos a la voluntad humana; no festeja la liberalidad dionisiaca sino la contención y claridad apolínea. A pesar de que Steiner señale al arte como promotor de la alienación, el autor chileno rescata y resalta la eterna y siempre presente luz de la revolución humana: "Cuando estoy triste o aburrido, dice Ansky en el cuaderno, aunque es difícil imaginar a Ansky aburrido, ocupado en huir las veinticuatro horas del día, pienso en Giuseppe Archimboldo y la tristeza y el tedio se evaporan" (911).

\section{Cierre}

¿Cuál puede ser la categoría más acertada para referir la forma en que se ha venido leyendo 2666? Wolfgang Iser viene en mi ayuda en una cita extensa pero sencilla y fascinante:

En el momento en que intentemos imponer al texto un esquema coherente, surgirán sin remedio discrepancias... Y es su presencia misma la que nos hace penetrar en el texto, obligándonos a realizar un examen creativo, no solamente del texto, sino también de nosotros mismos. Este enfrascamiento del lector es, por supuesto, vital para cualquier tipo de texto, pero en el texto literario nos encontramos con la extraña situación de que el lector no puede saber lo que realmente supone su participación. Sabemos que participamos de ciertas experiencias, pero no sabemos lo que ocurre en el transcurso de este proceso. Este es el motivo por el cual, cuando un libro nos ha impresionado particularmente, sentimos la necesidad de hablar de él... Hemos tenido una experiencia, y ahora queremos conocer conscientemente aquello que hemos experimentado. Quizás sea esta la utilidad primordial de la crítica literaria: ayudar a hacer conscientes aquellos aspectos del texto que de otro modo quedarían ocultos (236-7). 
Durante todo el siglo XX, lo que se entiende por siglo XX, es decir, desde 1914 en adelante, la literatura occidental y parte de la oriental se propuso descubrir la condición bestial del ser humano, se empeñó en sacar a la luz el horror que habita en los corazones, quizá como una forma de protesta o como un llamado de alerta, un recordatorio de la destrucción realizada y un clamor para que ésta no se repita. Y en esa misma vía, como parte del siglo, la historia le ha dado la razón a la literatura, empujándola para que no pierda el impulso, y marcándole el camino del caos para que siga reordenando, venciendo el dolor, convirtiéndolo en memoria, aliviando a los muertos de su carga de ignominia, humillación y silencio.

Esa es la labor del escritor según Bolaño, esto es lo que deja ver la categorización de algunos aspectos de 2666: el análisis arriba a la zona que la ética y la estética comparten, el lugar de enunciación donde la historia se pone en cuestión. La revisión hecha deja ver que por encima de todos los intereses estéticos y éticos propuestos por el autor, el de la lectura es el fundamental. La lectura desde el puente creado por el escritor permite cruzar el abismo y al mismo tiempo contemplar el oscuro caos que acompaña siempre a la humanidad. Es inevitable reconocer que el autor chileno marcó una ruta en donde el lector avanza desde la realidad racional hacia la realidad otra. El fin último es poner en diálogo la estética del juego y la ética de la revisión histórica.

En 2666 no podemos ver ni percibir el caos, ni el horror, ni entender su sentido si no es por medio de un lente, de una máquina traductora, de una máquina ordenadora. Eso es la obra literaria. La realidad, el mundo puro y duro es inaprensible, inasible, está al otro lado del abismo y es abismo. No lo veremos nunca tal cual. Para verlo es necesario el cerebro ordenador y el acto de creación. Y el lenguaje. La forma de la obra, ya sin tener en cuenta al autor, permite el juego y la posibilidad de indicar, desde la obra misma, el método para leer su estructura, y la ruta para analizarla e interpretarla. El proceso de separar para agrupar, logra que la mirada se detenga en zonas de la forma que están poco iluminadas. Luego de observarlas y proponer una interpretación, la evidencia constante es que 2666 es una obra abierta que mantiene la fuga narrativa como una de sus estrategias características: ni los micro-relatos, ni los relatos, ni los macro-relatos arriban a una "solución".

El esfuerzo de lectura del presente artículo consistió en buscar y definir una serie de isotopías que constituyen el entorno estético y temático de la novela, y que a la vez dan forma a dos grandes bloques: primero el de la realidad lógica, el mundo académico en donde priman las ideas, y luego el de la realidad otra, el mundo de la intemperie en donde priman los instintos y en donde la vida está en juego permanentemente. Bolaño construye una pantalla de televisión rota que, como en un sueño de Florita Almada, sigue transmitiendo imágenes en cada fragmento con autonomía de los demás y a la vez relacionándolos con el todo. Dichas imágenes pertenecen a los dos rangos arriba nombrados y determinan la realidad que se relata.

Por otro lado, la lectura dejó ver que esta diferencia entre la realidad racional y la realidad otra, desde una perspectiva conceptual, es sólo metodológica y que no 
determina tonos ni perspectivas en la narración. Las dos realidades coexisten en toda la novela, pero es claro también que en determinados momentos una prima sobre la otra. El concepto movimiento aparente reúne dicho enfoque estético.

Finalmente es preciso mencionar el valor ético de la literatura del chileno. El fantasma del compromiso social que siempre se elude pero que con Bolaño sale a la superficie de su creación para prender las alarmas sobre la necesidad y la debilidad de nuestra "inteligencia moral" (Steiner, En el castillo). Las obras de Bolaño nos llevan, sin ningún tipo de coerción o engaño, a volver sobre los cuestionamientos y las preocupaciones más actuales. A que, como lectores de novelas, miremos de frente y por primera vez tales situaciones. Por su parte los escritores deben jugarse la vida por la obra: "Ellos se enfrentarán, algunos hombro con hombro y otros más solos que la una, al reto de hacer de la literatura... algo razonable y visionario, un ejercicio de inteligencia, de aventura y de tolerancia. Si la literatura no es esto más placer, ¿qué demonios es?" (Bolaño, Entre 105).

\section{Referencias}

Benjamin, Walter. “Tesis de la filosofía de la historia”. Discursos interrumpidos I. Madrid: Taurus, 1973. 175-191. Medio impreso.

Bolaño, Roberto. Entre paréntesis. Barcelona: Anagrama, 2006. Medio impreso.

---. 2666. Barcelona: Anagrama, 2007. Medio impreso.

---. Los detectives salvajes. Barcelona: Anagrama, 2009. Medio impreso.

Calabrese, Omar. La era neobarroca. Madrid: Cátedra, 1987. Medio impreso.

Franz, Carlos. "Una tristeza insoportable. Ocho hipótesis sobre la mela-chole de B.." Bolaño salvaje. Comps. Edmundo Paz y Gustavo Faverón. Barcelona: Candaya, 2008. 103-115. Medio impreso.

Iser, Wolfgang. "El proceso de lectura: enfoque fenomenológico". Estética de la recepción. Comp. José A. Mayoral. Madrid: Arco, 1987. 215-243. Medio Impreso.

Kertesz, Imre. La lengua exiliada. Madrid: Taurus, 2007. Medio impreso.

Paz Soldán, Edmundo. "Roberto Bolaño: literatura y apocalipsis" [introducción]. Bolaño salvaje. Comps. Edmundo Paz y Gustavo Faverón. Barcelona: Candaya, 2008. 11-30. Medio impreso.

Saló o los 120 días de Sodoma. Dir. Pasolini, Pier Paolo. Act. Paolo Bonacelli, Aldo Valletti, Umberto Quintavalle. Blu-ray. Criterion Collection, 2011. Medio fílmico.

Sontag, Susan. Contra la interpretación y otros ensayos. Buenos Aires: Debolsillo, 2008. Medio impreso.

Steiner, George. En el castillo de Barba Azul. Aproximación a un nuevo concepto de cultura. Barcelona: Gedisa, 1992. Medio impreso.

---. Lenguaje y silencio. Ensayos sobre la literatura, el lenguaje y lo inhumano. Barcelona: Gedisa, 2003. Medio Impreso. 
Synecdoche, New York. Dir. Kaufman, Charlie. Act. Philip Seymour Hoffman, Catherine Keener, Emily Watson. Sony Pictures, 2008. Medio fílmico.

Villoro, Juan. "La batalla futura”. Bolaño Salvaje. Comps. Edmundo Paz y Gustavo Faverón. Barcelona: Candaya, 2008. 73-89. Medio impreso.

Recibido: 23 mayo 2013

Aceptado: 09 octubre 2013 